\title{
CORRELAÇÕES ENTRE VARIÁVEIS QUANTITATIVAS E QUALITATIVAS DE MILHO E DE SORGO PARA SILAGEM ${ }^{1}$
}

\author{
SOLIDETE DE FÁTIMA PAZIANI ${ }^{2}$, AILDSON PEREIRA DUARTE ${ }^{3}$, LUIZ GUSTAVO NUSSIO ${ }^{4}$, \\ ROGÉRIO SOARES DE FREITAS 5 , PAULO BOLLER GALLO ${ }^{6}$ e GUSTAVO PAVAN MATEUS 7
}

\author{
${ }^{1}$ Trabalho parcialmente financiado pela FUNDAG e FAPESP \\ ${ }^{2}$ Polo Regional Centro Norte/APTA/SAA, Rod. Washington Luiz, km 372, Pindorama/SP, Brasil, CEP: 15830-000, Caixa Postal 24, \\ solidete@apta.sp.gov.br \\ ${ }^{3}$ Instituto Agronomico de Campinas/APTA/SAA, Campinas/SP, aildson@iac.sp.gov.br \\ ${ }^{4} U S P / E S A L Q$, Piracicaba/SP,nussio@usp.br \\ ${ }^{5}$ Centro APTA de Seringueira e Sistemas Agroflorestais/IAC/APTA/SAA,Votuporanga/SP, freitas@iac.sp.gov.br \\ ${ }^{6} U P D$ de Mococa-IAC/APTA/SAA, Mococa/SP, paulogallo@iac.sp.gov.br \\ ${ }^{7}$ Polo Regional Extremo Oeste/APTA/SAA, Andradina/SP, gpmateus@apta.sp.gov.br
}

Revista Brasileira de Milho e Sorgo, v.18, n.3, p. 408-416, 2019

\begin{abstract}
RESUMO - O objetivo deste trabalho foi estabelecer correlações de Pearson entre variáveis quantitativas e qualitativas de milho e sorgo, visando definir os parâmetros mais importantes para predição do potencial produtivo e valor nutricional de forragem para silagem. Para sorgo, a produção de matéria seca (PMS) correlacionou-se $(\mathrm{P}<0,01)$ mais com a produção de grãos na ensilagem (PGE, 0,78), fração panícula $(0,55)$ e fração colmo $(-0,48)$. A digestibilidade da matéria seca (MS) da planta correlacionou-se significativamente com PGE $(0,57)$, PMS $(0,57)$, digestibilidade de colmo $(0,57)$ e teor de FDA da planta $(-0,62)$. A produção de matéria seca digestível (PMSDig) foi influenciada por PGE $(0,77)$, PMS $(0,95)$, fração panícula $(0,51)$, teor de FDA da planta $(-0,60)$ e digestibilidade da planta $(0,79)$. Para milho, a PMS foi mais influenciada pela PGE $(0,52)$ e a digestibilidade da planta foi mais influenciada por digestibiliade de colmo $(0,77)$, teor de FDA da planta $(-0,63)$ e teor de FDN da planta $(-0,62)$. A PMSdig de milho correlacionou mais com PGE $(0,50)$ e PMS $(0,91)$, digestibilidades de colmo $(0,59)$ e da planta $(0,74)$. Concluiu-se que, em ambas as culturas, as variáveis que mais contribuíram para maior PMSDig foram PMS, PGE e digestibilidade da planta.
\end{abstract}

Palavras-chave: Forragem, grãos, produtividade, valor nutritivo, Zea mays.

\section{CORRELATIONS BETWEEN QUANTITATIVE} AND QUALITATIVE CHARACTERISTICS OF MAIZE AND SORGHUM FOR SILAGE

\begin{abstract}
The objective of this study was to establish Pearson correlations between quantitative and qualitative variables of maize and sorghum for silage. For sorghum, dry matter production (DMP) was correlated ( $<0.01)$ with grain yield (EGP, 0.78), panicle fraction (0.55) and stem fraction (-0.48). The DM digestibility of the plant was significantly correlated with the EGP (0.57), DMP (0.57), stem digestibility (0.57) and plant ADF content (-0.62). The digestible dry matter production (DDMP) was influenced by EGP (0.77), DMS (0.95), panicle fraction (0.51), plant ADF content $(-0.60)$ and plant digestibility (0.79). For maize, DMP was more influenced by EGP (0.52). Plant digestibility was more influenced by stem digestibility (0.77), plant ADF content (-0.63) and plant NDF content (-0.62). The DDMP of maize was more correlated with EGP (0.50) and DMP (0.91), stem digestibility (0.59) and plant (0.74). As conclusion, the variables that most contributed to the highest DDMP were DMP, EGP and plant digestibility, for both cultures, Keywords: Forage, grains, yield, nutritive value, Zea mays.
\end{abstract}

Versão on line ISSN 1980-6477 - http://www.abms.org.br 
O milho e o sorgo são duas das culturas mais utilizadas na produção de forragem para ensilagem no Brasil, e a opção por cada uma delas depende de fatores como pacote tecnológico, custos de produção, condições edafoclimáticas regionais ou mesmo variações na época de semeadura ou nível de exigência nutricional do rebanho.

O milho é muito recomendado para produção de silagem por apresentar todos os requisitos desejáveis para silagem de alta qualidade, embora ocorram variações por fatores intrínsecos, como variedade, teor de grãos e digestibilidade. Esse cereal também varia de acordo com fatores extrínsecos, como condições climáticas (Deminicis et al., 2009), que influenciarão na produção, estrutura da planta e consequentemente na sua qualidade.

O sorgo tipo forrageiro, destinado à ensilagem, pode ser comparado ao milho em produção e valor nutritivo, porém, há grande variabilidade dentre os tipos disponíveis no mercado (granífero, forrageiro, sacarino, biomassa), o que influenciará a produção e o valor nutricional. Segundo Behling Neto et al. (2017), no Brasil, cultivares de sorgo graníferos são usualmente recomendadas para a produção de silagem de alta qualidade, por sua maior proporção de grãos, enquanto os sorgos forrageiros são recomendados para alta produção de matéria seca por hectare.

Assim, tanto para milho como para sorgo, um conjunto de características deve ser levado em consideração para ter uma planta equilibrada, destinada à ensilagem. Fatores isolados podem ser compensados por outros, por exemplo, uma planta de porte baixo pode ter sua menor produção de massa compensada pela maior produção de grãos ou ainda apresentar maior digestibilidade total da matéria seca, o que eleva a produtividade de nutrientes por área.
O milho e o sorgo podem ser igualmente produtivos, porém, devem ser consideradas as diferenças na arquitetura da planta e sua influência na qualidade nutricional da forragem obtida. Apenas para ilustrar o potencial de produção, Guareschi et al. (2010) compararam três híbridos de milho e três de sorgo em condições de cultivo sem adubação nitrogenada de cobertura e obtiveram produção média de matéria seca de 14,6 e de $16 \mathrm{t} \mathrm{MS} /$ ha para o milho e o sorgo, respectivamente.

Durante muito tempo, a cultivar de milho indicada para silagem foi baseada na elevada produção de matéria seca por hectare (Deminicis et al., 2009). Posteriormente, passou-se a considerar também a produção de grãos, sendo este, atualmente, o critério utilizado pelas companhias produtoras de semente para divulgar seus materiais para silagem. Zopollatto et al. (2009) observaram coeficiente de correlação de $0,72(\mathrm{P}<0,01)$ entre a produção de matéria seca e a produção de grãos de milho na ensilagem. Desta forma, o grão, além de contribuir na elevação da produtividade, também colabora na melhoria do valor nutritivo por ser composto basicamente de amido, nutriente de elevada digestibilidade e responsável por fornecer grande parte da energia da ração.

Falando-se de elevação na produtividade como um todo e na participação das espigas, o que elevaria a qualidade da silagem, Santos et al. (2010) observaram coeficiente de correlação negativo $(-0,77)$ entre produção de MS e participação de espigas na massa indicando o efeito de diluição das espigas com a elevação na produção de massa.

Há muitos fatores que influenciam na produção e na qualidade final da forragem para ensilagem. Muitos trabalhos são realizados objetivando estas avaliações, porém, a maioria deles realizados por apenas uma ou duas safras e em somente um local, o que 
pode levar a interações específicas com o ambiente e com as condições climáticas daquela safra, especialmente se forem anos atípicos. Por isso, ensaios de avaliação de cultivares em vários locais e safras, visando avaliar a correlação entre fatores produtivos e de valor nutritivo, são importantes, na busca por maiores produções e qualidade da silagem final, seja de milho ou de sorgo, eliminando possíveis efeitos de interação edafoclimáticas e safras atípicas, dando maior consistência aos dados.

Quando se fala em correlações entre características de interesse, Crevelari et al. (2018) citam que o rendimento de matéria fresca é um traço complexo, que resulta da associação entre muitas características. A intensidade dessa associação, determinada por estudos de correlação, permite identificar características que podem ser utilizadas como critérios indiretos de seleção de produtividade.

O objetivo deste trabalho foi estudar as correlações entre variáveis quantitativas e qualitativas de milho e de sorgo na produção de forragem para silagem, visando determinar as variáveis mais bem correlacionadas com o potencial produtivo e valor nutritivo das cultivares.

\section{Material e Métodos}

Os experimentos foram instalados por cinco safras (2004/05 a 2008/09) nos municípios de Assis, Mococa, Pindamonhangaba, Votuporanga, Andradina e Itapetininga, no Estado de São Paulo, em unidades da APTA/SAA, totalizando 17 ambientes (safra x local), porém, nem todos os locais se repetiram em todas as safras. O delineamento experimental foi em blocos casualizados com quatro repetições, semeandose no mesmo ensaio seis cultivares de milho (30F90, 30S40, AG1051, AGN2012, AL Piratininga e Tork) e três cultivares de sorgo forrageiro (BRS610, 1F305 e Volumax) em todas as safras. As parcelas consistiam de seis linhas de $5 \mathrm{~m}$ de comprimento, sendo duas linhas laterais às bordaduras e as duas linhas centrais utilizadas para as avaliações no ponto de corte para silagem.

As plantas foram colhidas com teor de MS médio de $35 \%$, sendo medidas suas alturas. Em seguida, as plantas de milho foram fracionadas em colmo + pendão (FRACOL), folhas (FRAFOL) e espigas (FRAESP). No caso do sorgo foram as frações colmo, folhas e panículas (FRAPAN). Estas frações foram pesadas, secas e pesadas novamente. Amostras de plantas inteiras e colmos triturados foram secas a $65^{\circ} \mathrm{C}$ por 72 horas para determinação do teor de matéria seca (MS), e foi realizada a estimativa de composição bromatológica de acordo com a metodologia do NIRS (Shenk \& Westerhaus, 1991), para digestibilidade in vitro da matéria seca (DIVMS), fibra em detergente neutro (FDN) e fibra em detergente ácido (FDA). Após a secagem das espigas e panículas os grãos foram retirados e pesados.

Foram estimadas as produções de matéria seca (PMS) e de grãos na ensilagem (PGE). A produção de matéria seca digestível (PMSDig) foi calculada multiplicando-se a produção de matéria seca $\left(\mathrm{kg}\right.$. ha- $\left.{ }^{-1}\right)$ pela respectiva digestibilidade da matéria seca da planta inteira.

Os dados foram submetidos à análise de variância utilizando o Statistical Analysis System (SAS Institute, 1990). As principais variáveis quantitativas e qualitativas foram submetidas à análise de correlação de Pearson (PROC COR, SAS), utilizando-se as médias das quatro repetições de cada cultivar em cada ambiente. As médias das variáveis do milho versus as do sorgo foram comparadas pelo teste Tukey a $5 \%$. 


\section{Resultados e Discussão}

Na Tabela 1 são apresentadas as médias das variáveis nas culturas de milho e sorgo e seus respectivos coeficientes de variação.

Não houve diferença estatística entre as produções de matéria seca e de grãos no momento da ensilagem para milho e sorgo (Tabela 1). Considerando as produtividades de milho de $6 \mathrm{t} /$ ha de grãos e de 17 t/ha MS e de sorgo de 7 t/ha de grãos e de 18 t/ha de MS, equivale dizer que milho e sorgo apresentaram 35 e 39\% de grãos na massa seca, respectivamente. Um fato a ser observado é que no milho houve maior participação das espigas (55\%) do que de panículas no sorgo ( $32 \%$ da MS). Se no milho a proporção de espigas foi maior do que a proporção de panículas no sorgo (55 x 32\% da MS), mas isso não refletiu em maior proporção de grãos na matéria seca no milho, esta diferença pode ser atribuída ao menor rendimento de grãos nas espigas do que nas panículas de sorgo.

A digestibilidade de planta toda de sorgo foi menor do que a do milho (53 x 59\% da MS, respectivamente), provavelmente devido aos maiores teores de FDN e FDA da planta inteira.

Crevelari et al. (2018) avaliando 15 cultivares de milho para silagem obtiveram $6 \mathrm{t}$ /ha de grãos no momento da ensilagem e produção de massa verde de 37 t/ha, o que equivale a $17 \%$ de grãos na massa ver-

Tabela 1. Valores médios das características agronômicas e bromatológicas de milho e sorgo na ensilagem.

\begin{tabular}{|c|c|c|c|c|}
\hline \multicolumn{2}{|l|}{ Variável $^{1}$} & Milho $^{2}$ & Sorgo & $\mathrm{cv}^{3}$ \\
\hline \multicolumn{2}{|l|}{$\mathrm{AP}, \mathrm{cm}$} & $217^{\mathrm{a}}$ & $211^{b}$ & 13,8 \\
\hline \multicolumn{2}{|l|}{ PGE, t/ha } & $6^{\mathrm{a}}$ & $7^{\mathrm{a}}$ & 41,7 \\
\hline \multicolumn{2}{|l|}{ PMS, t ha-1 } & $17^{\mathrm{a}}$ & $18^{\mathrm{a}}$ & 24,2 \\
\hline \multicolumn{2}{|c|}{ Fração folhas, \% da MS } & $18^{\mathrm{b}}$ & $22^{\mathrm{a}}$ & 26,4 \\
\hline \multicolumn{2}{|c|}{ Fração colmos, \% da MS } & $27^{b}$ & $46^{\mathrm{a}}$ & 23,8 \\
\hline \multicolumn{2}{|c|}{ Fração espiga/panícula, \% da MS } & $55^{\mathrm{a}}$ & $32^{b}$ & 17,6 \\
\hline \multicolumn{2}{|c|}{ PMSDig, $\mathrm{t} \mathrm{ha}^{-1}$} & $10^{\mathrm{a}}$ & $10^{\mathrm{a}}$ & 15,1 \\
\hline \multicolumn{2}{|c|}{ Composição bromatológica } & Milho* & Sorgo & $\mathrm{cv}^{3}$ \\
\hline \multirow[t]{3}{*}{ Planta inteira } & $\mathrm{FDA}, \%$ da $\mathrm{MS}$ & $27^{b}$ & $32^{\mathrm{a}}$ & 14,9 \\
\hline & $\mathrm{FDN}, \%$ da $\mathrm{MS}$ & $54^{b}$ & $57^{\mathrm{a}}$ & 18,9 \\
\hline & DIVMS, $\%$ da MS & $59^{\mathrm{a}}$ & $53^{\mathrm{b}}$ & 13,4 \\
\hline \multirow[t]{3}{*}{ Colmo } & $\mathrm{FDA}, \%$ da $\mathrm{MS}$ & $41^{\mathrm{a}}$ & $41^{\mathrm{a}}$ & 15,1 \\
\hline & $\mathrm{FDN}, \%$ da $\mathrm{MS}$ & $68^{\mathrm{a}}$ & $69^{\mathrm{a}}$ & 9,5 \\
\hline & DIVMS, \% & $47^{\mathrm{a}}$ & $47^{\mathrm{a}}$ & 16,7 \\
\hline
\end{tabular}

${ }^{1} \mathrm{MS}=$ matéria seca; PMS = produção de MS; PGE = produção de grãos na ensilagem; AP = altura de planta; PMSDig = produção de matéria seca digestível; FDA = fibra em detergente ácido; FDN = fibra em detergente neutro; DIVMS = digestibilidade in vitro da MS. ${ }^{2}$ Médias seguidas pela mesma letra na linha não diferem pelo teste de Tukey $(\mathrm{p}<0,05)$ ${ }^{3} \mathrm{cv}=$ coeficiente de variação 
de, com produção de grãos próxima às 6 t/ha observadas neste trabalho. Assim a produtividade de grãos na ensilagem gerou uma correlação de 0,64 com a produção de massa verde e de 0,81 com o teor de grãos na massa verde, indicando a importância da presença do grão na produtividade total.

Para sorgo, são encontrados na literatura valores de FDN entre 38 e $67 \%$, para FDA valores de 30 a $35 \%$ e digestibilidade da MS in vitro entre $61 \mathrm{e}$ 68\% (Moura et al., 2016; Behling Neto et al., 2017; Oliveira et al., 2018; Tolentino et al., 2016; Veriato et al., 2018). Portanto, os valores de 57\% de FDN e 32\% de FDA de planta de sorgo neste trabalho situam-se dentro de faixas observadas literatura.

Para milho, Oliveira et al. (2017), coletando silagens de milho em fazendas, observaram teor de
$52 \%$ de FDN, próximo aos 54\% do presente trabalho, mas digestibilidade da MS in vitro de $65 \%$, acima dos $59 \%$ aqui observados. Estes autores concluíram que a silagem de milho produzida em fazendas intensivas do Brasil tem valor nutritivo satisfatório para clima tropical, no entanto, algumas características não são adequadas, como a concentração de FDN e sua digestibilidade.

Quanto às correlações entre as variáveis, na cultura do milho (Tabela 2), a produção de matéria seca foi mais influenciada pela produção de grãos no ponto de colheita para silagem $(0,52)$. Zopollatto et al. (2009) observaram o coeficiente de correlação entre a produção de grãos de milho na ensilagem e produção de matéria seca de 0,72 , superior à deste trabalho.

Tabela 2. Correlações de Pearson entre as variáveis em milho ( $\mathrm{n}=334$ a 406).

\begin{tabular}{|c|c|c|c|c|c|c|c|c|c|c|c|c|}
\hline MILHO & $\mathrm{AP}$ & PGE & PMS & FRAFOL & FRACOL & FRAESP & FDAc & FDNc & DIVMSc & FDAp & FDNp & DIVMSp \\
\hline \multicolumn{13}{|l|}{$\mathrm{AP}^{1}$} \\
\hline PGE & NS & & & & & & & & & & & \\
\hline PMS & $0,28 * *$ & $0,52 * *$ & & & & & & & & & & \\
\hline FRAFOL & NS & $-0,29 * *$ & NS & & & & & & & & & \\
\hline FRACOL & $0,35^{* *}$ & $-0,14 * *$ & NS & $-0,37 * *$ & & & & & & & & \\
\hline FRAESP & $-0,31^{* *}$ & $0,37 * *$ & NS & $-0,48 * *$ & $-0,64 * *$ & & & & & & & \\
\hline FDAc & $0,14^{*}$ & NS & $-0,20^{* *}$ & $0,12^{*}$ & $0,14^{* *}$ & NS & & & & & & \\
\hline $\mathrm{FDNc}$ & NS & NS & $-0,28 * *$ & NS & $-0,20 * *$ & $0,14^{* *}$ & $0,78 * *$ & & & & & \\
\hline DIVMSc & NS & $0,26^{* *}$ & $0,34 * *$ & $-0,19^{* *}$ & NS & $0,17^{* *}$ & $-0,31 * *$ & $-0,54 * *$ & & & & \\
\hline FDAp & NS & $-0,19 * *$ & $-0,26^{* *}$ & $0,15^{* *}$ & $0,14^{* *}$ & $-0,26^{* *}$ & $0,39 * *$ & $0,39^{* *}$ & $-0,45 * *$ & & & \\
\hline FDNp & NS & $-0,19 * *$ & $-0,31^{* *}$ & NS & NS & NS & $0,28 * *$ & $0,49 * *$ & $-0,44 * *$ & $0,68 * *$ & & \\
\hline DIVMSp & NS & $0,31 * *$ & $0,41^{* *}$ & $-0,10^{*}$ & $-0,17^{* *}$ & $0,25^{* *}$ & $-0,12 *$ & $-0,32 * *$ & $0,77 * *$ & $-0,63 * *$ & $-0,62^{* *}$ & \\
\hline PMSDig & $0,24^{* *}$ & $0,50^{* *}$ & $0,91 * *$ & NS & NS & $0,14^{* *}$ & $-0,19 * *$ & $-0,36^{* *}$ & $0,59 * *$ & $-0,46^{* *}$ & $-0,49 * *$ & $0,74^{* *}$ \\
\hline
\end{tabular}

$* * \mathrm{p}<0,01 \% ; * \mathrm{p}<0,05 \%$; NS = não significativo

${ }^{1} \mathrm{AP}=$ altura de planta; $\mathrm{PGE}=$ produção de grãos na ensilagem; PMS = produção de matéria seca; FRAFOL = fração folha; FRACOL

= fração colmo; FRAESP $=$ fração espiga; FDAc $=$ teor de FDA do colmo; FDNc $=$ teor de FDN do colmo; DIVMSc $=$ digestibilidade in vitro da MS do colmo; FDAp = teor de FDA da planta; FDNp = teor de FDN da planta; DIVMSp = digestibilidade in vitro da MS da planta; PMSDig = produção de matéria seca digestível 
A produção de MS neste trabalho apresentou correlação de 0,28 com a altura de plantas, que apesar de positiva foi baixa. Domingues et al. (2013) obtiveram correlação de 0,80 entre produção de massa verde e altura de planta, valor próximo aos 0,75 observado por Crevelari et al. (2018) para as mesmas variáveis, fator que fez estes últimos autores indicarem a possibilidade de seleção indireta das plantas mais altas visando maior produtividade de massa verde.

A elevação na altura da planta, contribuindo no aumento da produtividade de massa, é um fato esperado uma vez que plantas mais altas podem produzir maior volume de massa se as frações folhas, espigas e grãos também forem elevadas. Porém, no presente trabalho, o aumento na altura da planta teve efeito negativo na participação da fração espiga $(-0,31)$ e positiva na participação da fração colmo $(0,35)$, o que mostrou um efeito de diluição de espigas na massa, nenhuma influência da fração de folhas e apenas o colmo contribuindo com aumento na produtividade, fato não muito interessante, uma vez que o colmo é a porção mais fibrosa e pode reduzir a digestibiliade da planta como um todo. Portanto, uma cultivar mais alta é interessante se também tiver maior potencial de produção de grãos.

Com relação ao valor nutritivo da forragem de milho, a digestibilidade foi influenciada positivamente pela digestibilidade de colmo $(0,77)$, mas negativamente pelos teores de FDA $(-0,63)$ e de FDN da planta $(-0,62)$, evidenciando a importância da digestibilidade do colmo (Tabela 2). A disgestibilidade do colmo também diminuiu com o aumento no seu teor de FDA e FDN, observado através das correlações $-0,31$ e $-0,54$, respectivamente.

Quanto à produção de matéria seca digestível, resultante da associação entre produção de matéria seca e a digestibilidade da planta, correlacionou-se mais fortemente com a produção de grãos na ensilagem $(0,50)$, produção de matéria seca $(0,91)$, digestibilidade de colmo $(0,59)$ e digestibilidade da planta $(0,74)$. Assim a produção de matéria seca digestível (Tabela 2) está associada à produção de massa total e também sofre influência da produção de grãos no momento da ensilagem, além de ser afetada negativamente pelos teores de FDN e FDA tanto de colmo como de planta toda.

Não ocorreram correlações significativas entre produção de matéria seca de milho e as frações folhas, colmos e espigas. Santos et al. (2010) observaram elevado coeficiente de correlação entre participação de folha e produção de MS $(0,86)$, com elevação da produção de MS diluindo a participação de espigas $(-0,77)$. Apesar de Santos et al. (2010) terem obtido participações na MS de 53\% para espigas, 28\% para colmo e 19\% para folhas, portanto valores bem próximos aos do presente trabalho, estes dados foram obtidos de apenas uma safra e um local.

Crevelari et al. (2018) reconhecem que a seleção de híbridos de milho para silagem pode se tornar difícil em razão da complexidade entre as características que contribuem na produtividade de massa. Assim, afirmam que, selecionando híbridos com maior proporção de espiga, indiretamente obtêm maior rendimento de matéria fresca, pois obtiveram 0,91 de correlação entre estas variáveis.

Quanto ao sorgo (Tabela 3), no presente trabalho a altura de planta correlacionou-se de forma positiva com produção de MS $(0,53)$, produção de grãos na ensilagem $(0,57)$ e com a fração panícula $(0,38)$, em detrimento das frações colmo $(-0,26)$ e folhas $(-0,29)$. Houve forte correlação negativa da fração colmo com a fração panícula $(-0,88)$, indicando forte efeito de diluição das panículas em plantas mais altas. Perazzo et al. (2014), ao avaliar 32 cultivares de 
sorgo em único local e safra, obtiveram coeficiente de correlação de 0,61 entre altura de planta e produção de matéria seca.

A produção de matéria seca do sorgo correlacionou-se positivamente $(\mathrm{P}<0,01)$ com a produção de grãos na ensilagem $(0,78)$ e fração panícula $(0,55)$ (Tabela 3).

Quanto ao valor nutritivo do sorgo, a digestibilidade da MS da planta correlacionou-se significativamente de forma positiva com a produção de grãos na ensilagem $(0,57)$, produção de matéria seca $(0,57)$, digestibilidade de colmo $(0,57)$, mas foi afetada de forma negativa pelas frações colmo $(-0,24)$ e folha $(-0,32)$. É interessante notar que no sorgo as frações folha e colmo afetaram de forma mais negativa a digestibilidade da matéria seca de planta toda do que no milho, possivelmente por causa da maior variabilidade na arquitetura da planta e de maiores valores de FDN e FDA no sorgo do que no milho (Tabela 1).

A produção de matéria seca digestível do sorgo foi mais influenciada pela altura de planta $(0,48)$, produção de grãos no momento da ensilagem $(0,77)$, produção de matéria seca $(0,95)$, fração panícula $(0,51)$ e digestibilidade da planta $(0,79)$ e de colmo $(0,39)$, conforme dados da Tabela 3.

Comparando as correlações entre milho e sorgo, a produção de matéria seca foi mais influenciada pela produção de grãos na ensilagem no sorgo do que no milho $(0,78 \times 0,52)$. Também a produção de matéria seca do sorgo foi influenciada pela altura de planta $(0,53)$ enquanto no milho não houve correlação significativa.

Tabela 3. Correlações de Pearson entre as variáveis em sorgo ( $\mathrm{n}=120$ a 202).

\begin{tabular}{|c|c|c|c|c|c|c|c|c|c|c|c|c|}
\hline SORGO & AP & PGE & PMS & FRAFOL & FRACOL & FRAPAN & FDAc & FDNc & DIVMSc & FDAp & FDNp & DIVMSp \\
\hline \multicolumn{13}{|l|}{$\mathrm{AP}^{1}$} \\
\hline PGE & $0,57 * *$ & & & & & & & & & & & \\
\hline PMS & $0,53 * *$ & $0,78 * *$ & & & & & & & & & & \\
\hline FRAFOL & $-0,29 * *$ & $-0,50 * *$ & $-0,22 * *$ & & & & & & & & & \\
\hline FRACOL & $-0,26^{* *}$ & $-0,69 * *$ & $-0,48 * *$ & NS & & & & & & & & \\
\hline FRAPAN & $0,38 * *$ & $0,88 * *$ & $0,55^{* *}$ & $-0,41 * *$ & $-0,88^{* *}$ & & & & & & & \\
\hline FDAc & NS & $0,38 * *$ & NS & $-0,28 * *$ & $-0,34 * *$ & $0,44 * *$ & & & & & & \\
\hline FDNc & NS & NS & NS & NS & $-0,30 * *$ & $0,27 * *$ & $0,70 * *$ & & & & & \\
\hline DIVMSc & $0,32 * *$ & $0,27 * *$ & $0,24 * *$ & $-0,28 * *$ & NS & NS & $-0,44 * *$ & $-0,69 * *$ & & & & \\
\hline FDAp & $-0,36^{* *}$ & $-0,67 * *$ & $-0,52 * *$ & $0,38^{* *}$ & $0,44 * *$ & $-0,58 * *$ & NS & NS & $-0,37 * *$ & & & \\
\hline FDNp & $0,19 * *$ & $-0,68 * *$ & NS & NS & NS & NS & $-0,28 * *$ & NS & NS & NS & & \\
\hline DIVMSp & $0,27 * *$ & $0,57 * *$ & $0,57 * *$ & $-0,32 * *$ & $-0,24 *$ & $0,37 * *$ & $-0,14 *$ & $-0,20 * *$ & $0,57 * *$ & $-0,62 * *$ & NS & \\
\hline PMSDig & $0,48 * *$ & $0,77 * *$ & $0,95 * *$ & $-0,29 * *$ & $-0,40 * *$ & $0,51 * *$ & NS & NS & $0,39 * *$ & $-0,60 * *$ & NS & $0,79 * *$ \\
\hline
\end{tabular}

$* * \mathrm{p}<0,01 \% ; * \mathrm{p}<0,05 \%$; NS = não significativo

${ }^{1} \mathrm{AP}=$ altura de planta; $\mathrm{PGE}=$ produção de grãos na ensilagem; PMS = produção de matéria seca; FRAFOL = fração folha; FRACOL = fração colmo; FRAPAN = fração panícula; FDAc $=$ teor de FDA do colmo; FDNc $=$ teor de FDN do colmo; DIVMSc $=$ digestibilidade in vitro da MS do colmo; FDAp = teor de FDA da planta; FDNp = teor de FDN da planta; DIVMSp = digestibilidade in vitro da MS da planta; PMSDig = produção de matéria seca digestível 
Enquanto no milho as correlações não foram significativas entre a produção de matéria seca e as frações individuais da planta (folhas, colmos e espigas), no sorgo estas influências foram marcantes, com grande dependência da fração panícula. Talvez este ocorrido demonstre que as cultivares de milho do mercado sejam mais uniformes em arquitetura, e as diferentes frações não manifestaram correlações tão significativas como no sorgo, o qual pode possuir estrutura mais heterogênea dentre as cultivares.

Quanto à digestibilidade da planta, no sorgo, esta foi mais afetada pela fração panícula do que pela fração espiga no milho $(0,37$ x 0,25$)$. Com relação à digestibilidade de colmo, esta afetou a digestibilidade de planta mais no milho do que no sorgo $(0,77 \times 0,57)$. Também pode ser notado, tanto para milho como para sorgo, que a fração espiga tem correlação negativa com as frações colmo e folhas, o que é esperado por causa do efeito de diluição entre estas frações.

A alta porcentagem de fibra é uma característica indesejável para milho e sorgo para ensilagem, correlacionando-se negativamente com a digestibilidade da matéria seca (Oliveira et al., 2010), o que também limitaria a ingestão pelo animal. Porém, o teor de fibra pode ser diluído na massa de forragem à medida que se eleva o potencial de produção de grãos e também pode ter menor efeito negativo à medida que a fibra apresenta maior potencial digestível, principalmente a fibra do colmo das plantas. Assim, no presente trabalho a produção de matéria seca digestível, tanto de sorgo como de milho, é beneficiada pela produção de matéria seca (0,95 e 0,91, respectivamente), produção de grãos na ensilagem $(0,77$ e 0,50 , respectivamente) e digestibilidade da planta $(0,79$ e 0,74$)$. Porém, no sorgo há maior benefício da presença das panículas e maior prejuízo do teor de FDA da planta.

\section{Conclusões}

A produtividade de grãos no momento da ensilagem foi um fator que contribuiu de forma positiva na elevação da produção de matéria seca, tanto no milho como no sorgo, assim como também reduziu a proporção de folhas e colmos, elevou a digestibilidade de planta e consequentemente também a produtividade de matéria seca digestível. A altura de planta tem mais influência na produtividade de matéria seca do sorgo do que de milho, e o fracionamento da planta interfere mais na digestibilidade da MS na planta no sorgo, em comparação ao milho.

\section{Agradecimentos}

Às unidades da APTA, ao Departamento de Zootecnia da USP/ESALQ, FAPESP e FUNDAG.

\section{Referências}

BEHLING NETO, A.; REIS, R. H. P.; CABRAL, L. S.; ABREU, J. G.; SOUSA, D. P.; SOUSA, F. G Nutritional value of sorghum silage of different purposes. Ciência e Agrotecnologia, v. 41, n. 3, p. 288-299, 2017. DOI: $10.1590 / 1413-70542017413038516$.

CREVELARI, J. A.; DURÃES, N. R. L.; BENDIA, L. C. R.; VETTORAZZI, J. C. F.; ENTRINGER, G. C.; FERREIRA JÚNIOR, J. A.; PEREIRA, M. G. Correlations between agronomic traits and path analysis for silage production in maize hybrids. Bragantia, v. 77, n. 2, p. 243$252,2018$.

DOI: $10.1590 / 1678-4499.2016512$.

DEMINICIS, B. B.; VIEIRA, H. D.; JARDIM, J. G.; ARAÚJO, S. A. C.; CHAMBELA NETO, A.; OLIVEIRA, V. C.; LIMA, E. S. Silagem de milho: características agronômicas e considerações. REDVET. Revista 
Electrónica de Veterinária, v. 10, n. 2, p. 1-18, 2009.

Disponível em: <http://www.veterinaria.org/revistas/ redvet/n020209.html>. Acesso em: 10 jun. 2019.

DOMINGUES, A. N.; ABREU, J. G.; CANEPPELE, C.; REIS, R. H. P.; BEHLING NETO, A.; ALMEIDA, C. M. Agronomic characteristics of corn hybrids for silage production in the State of Mato Grosso, Brazil. Acta Scientiarum. Animal Sciences, v. 35, n. 1, p. 7-12, 2013. DOI: 10.4025/actascianimsci.v35i1.15592.

GUARESCHI, R. F.; BRASIL, R. B.; PERIN,A.; RIBEIRO, J. M. M. Produção de silagem de híbridos de milho e sorgo sem nitrogênio de cobertura em safra de verão. Pesquisa Agropecuária Tropical, v. 40, n. 4, p. 541-546, out./dez. 2010. DOI: $10.1590 / \mathrm{S} 1983-40632010000400016$.

MOURA, M. M. A.; PIRES, D. A. A.; RODRIGUES, J. A. S.; SALES, E. C. J.; COSTA, R. F.; TOLENTINO, D. C. Chemical composition of sorghum genotypes silages. Acta Scientiarum. Animal Sciences, v. 38, n. 4, p. 369373, 2016. DOI: 10.4025/actascianimsci.v38i4.31810.

OLIVEIRA, L. B.; PIRES, A. J. V.; CARVALHO, G. G. P.; RIBEIRO, L. S. O.; ALMEIDA, V. V.; PEIXOTO, C. A. M. Perdas e valor nutritivo de silagens de milho, sorgosudão, sorgo forrageiro e girassol. Revista Brasileira de Zootecnia, v. 39, n. 1, p. 61-67, 2010.

DOI: $10.1590 / \mathrm{S} 1516-35982010000100008$.

OLIVEIRA, I. L.; LIMA, L. M.; CASAGRANDE, D. R.; LARA, M. A. S.; BERNARDES, T. F. Nutritive value of corn silage from intensive dairy farms in Brazil. Revista Brasileira de Zootecnia, v. 46, n. 6, p. 494-501, 2017. DOI: 10.1590/s1806-92902017000600004.

OLIVEIRA, B. S.; PEREIRA, L. G. R.; AZEVÊDO, J. A. G.; RODRIGUES, J. A. S.; VELASCO, F. O.; NEVES, A. L. A.; MAURÍCIO, R. M.; VERNEQUE, R. S.; SANTOS, R. D. Silage quality of six sorghum cultivars for sheep. Pesquisa Agropecuária Brasileira, v. 53, n. 2, p. 256264, 2018. DOI: 10.1590/S0100-204X2018000200015.
PERAZZO, A. F.; CARVALHO, G. G. P.; SANTOS, E. M.; PINHO, R. M. A.; CAMPOS, F. S.; MACEDO, C. H. O.; AZEVÊDO, J.A. G.; TABOSA, J. N. Agronomic evaluation of 32 sorghum cultivars in the Brazilian semi-arid region. Revista Brasileira de Zootecnia, v. 43, n. 5, p. 232-237, 2014. DOI: $10.1590 / \mathrm{S} 1516-35982014000500002$.

SANTOS, R. D.; PEREIRA, L. G. R.; NEVES, A. L. A.; AZEVÊDO, J. A. G.; MORAES, S. A.; COSTA, C. T. F. Características agronômicas de variedades de milho para produção de silagem. Acta Scientiarum. Animal Sciences, v. 32, n. 4, p. 367-373, 2010.

DOI: 10.4025 /actascianimsci.v32i4.9299.

SHENK, J. S.; WESTERHAUS, M. O. Population definition. sample selection. and calibration procedures for near infrared reflectance spectroscopy. Crop Science, v. 31, n. 2, p. 469-474, 1991.

DOI: 10.2135/cropsci1991.0011183X003100020049x.

SAS INSTITUTE. Statistical Analysis System - SAS: user's guide: version 6. 4. ed. Cary, 1990. 956 p.

TOLENTINO, D. C.; RODRIGUES, J. A. S.; PIRES, D. A. A.; VERIATO, F. T.; LIMA, L. O. B.; MOURA, M. M. A. The quality of silage of different sorghum genotypes. Acta Scientiarum. Animal Sciences, v. 38, n. 2, p. 143-149, 2016. DOI: 10.4025 /actascianimsci.v38i2.29030.

VERIATO, F. T.; PIRES, D. A. A.; TOLENTINO, D. C.; ALVES, D. D.; JAYME, D. G.; MOURA, M. M. A. Fermentation characteristics and nutritive values of sorghum silages. Acta Scientiarum. Animal Sciences, v. 40, e34458, 2018.

DOI: 10.4025 /actascianimsci.v40i1.34458.

ZOPOLLATTO, M.; NUSSIO, L. G.; PAZIANI, S. F.; RIBEIRO, J. L.; SARTURI, J. O.; MOURÃO, G. B. Relações biométricas entre o estádio de maturação e a produção de híbridos de milho para produção de silagem. Revista Brasileira de Zootecnia, v. 38, n. 2, p. 256-264, 2009. DOI: $10.1590 / \mathrm{S} 1516-35982009000200006$. 